Cambridge University Press

978-1-107-07142-1 - Dynamics and Predictability of Large-Scale High-Impact Weather and Climate Events

Edited by Jianping Li, Richard Swinbank, Richard Grotjahn and Hans Volkert

Frontmatter

More information

\title{
Dynamics and Predictability of Large-Scale, High-Impact Weather and Climate Events
}

In recent years, a significant number of high-impact weather and extreme climate events have inflicted catastrophic property damage, and loss of human life, around the world, and hindered socio-economic development. Improving simulation and prediction of these events is an increasingly important requirement of public meteorological services

Based largely on an International Commission on Dynamical Meteorology (ICDM) workshop, this timely volume covers a range of important research issues related to extreme events. Dynamical linkages between these extremes and various atmospheric and ocean phenomena are examined, including Atlantic Multi-decadal, North Atlantic, and Madden-Julian Oscillations, Annular Modes, tropical cyclones, and Asian monsoons. This book also examines the predictability of high-impact weather and extreme climate events on multiple time scales. Highlighting recent research and new advances in the field, this book enhances understanding of dynamical and physical processes associated with these events, to help managers and policy makers make informed decisions to manage risk and prevent or mitigate disasters. It also provides guidance on future research directions for experts and young scientists.

Written by leading researchers in weather and climate extremes, this comprehensive volume is ideal for professionals and policy makers working in disaster prevention and mitigation, and is a key resource for graduate students and academic researchers in atmospheric science, meteorology, climate science, and weather forecasting.

JiANPING LI is Dean and Professor at the College of Global Change and Earth System Sciences (GCESS), Beijing Normal University, and Director of the Joint Center for Global Change Studies (JCGCS). He is also an affiliated faculty member of the University of Hawaii, a Fellow of the International Union of
Geodesy and Geophysics (IUGG), and a Fellow of the Royal Meteorological Society. His major research interests include climate dynamics and climate change, predictability, monsoons, and annular modes. He is Vice-Chair of the IUGG Commission on Climatic and Environmental Change (CCEC), and Executive Secretary of the International Commission of Climate (ICCL) within IAMAS (International Association of Meteorology and Atmospheric Sciences)

Richard SWINBAnk is a Scientific Manager in Weather Science at the Met Office in the UK and a Fellow of the Royal Meteorological Society. He is past President of the IAMAS International Commission on Dynamical Meteorology (ICDM) and Co-Chair of the World Weather Research Programme (WWRP) working group on Predictability, Dynamics, and Ensemble Forecasting (PDEF). His research interests include ensemble forecasting, data assimilation, atmospheric dynamics, and predictability of high-impact weather.

Richard Grotjahn is (upper level) Professor of Climate Dynamics at the University of California, Davis, California, USA. He is currently President of the ICDM commission of IAMAS, and is Co-Chair of the US CLIVAR working group on Large Scale Circulation Patterns Associated with Extremes. His research interests include extreme weather, climate model assessment, and large-scale atmospheric synoptic-dynamics.

Hans Volkert is Senior Scientist at the Deutsches Zentrum für Luft-und Raumfahrt (DLR), Institut für Physik der Atmosphäre (IPA), Germany, and a Fellow of the Royal Meteorological Society. He served as Secretary-General of IAMAS from 2007 to 2015 and as IUGG liaison officer to the World Meteorological Organization (WMO) from 2011 to 2015, with a focus on atmospheric issues. His main research interests are in mesoscale meteorology, weather forecasting, and the development of meteorology as a branch of physics. 
Cambridge University Press

978-1-107-07142-1 - Dynamics and Predictability of Large-Scale High-Impact Weather and Climate Events

Edited by Jianping Li, Richard Swinbank, Richard Grotjahn and Hans Volkert

Frontmatter

More information

\section{Special publications of the International Union of Geodesy and Geophysics Series}

The International Union of Geodesy and Geophysics (IUGG) promotes and co-ordinates international scientific studies of Earth (physical, chemical, and mathematical) and its environment in space, aiming to apply this knowledge to societal needs such as mineral resources, mitigation of natural hazards, and environmental preservation. The series is co-published by the IUGG and Cambridge University Press, providing researchers and graduate students with authoritative insights into major scientific developments and state-ofthe-art research.

\section{SERIES EDITORS}

Christophe Cudennec, Agrocampus Ouest, Rennes, France

Hermann Drewes, Deutsches Geodätisches Forschungsinstitut, Munich, Germany

Alik Ismail-Zadeh, (Editor-in-chief), Karlsruhe Institute of Technology, Germany

Andrew Mackintosh, Victoria University of Wellington, New Zealand

Mioara Mandea, Centre National d'Etudes Spatiale, Paris, France

Joan Martí, Instituto de Ciencias de la Tierra "Jaume Almera", Barcelona, Spain

Johan Rodhe, University of Gothenburg, Sweden

Peter Suhadolc, University of Trieste, Italy

Hans Volkert, Deutsches Zentrum für Luft-und Raumfahrt, Oberpfaffenhofen, Germany

\section{ADVISORY BOARD}

Ian Allison, Antarctic Climate \& Ecosystems CRC, Hobart, Australia

Isabelle Ansorge, University of Cape Town, South Africa

Tom Beer, Commonwealth Scientific and Industrial Research Organisation, Australia

Claudio Brunini, Universidad Nacional de La Plata, Argentina

Jeff Freymueller, University of Alaska, Fairbanks

Harsh Gupta, National Geophysical Research Institute, Hyderabad, India

David Jackson, University of California, Los Angeles

Setsuya Nakada, University of Tokyo, Japan

Guoxiong Wu, Chinese Academy of Sciences, Beijing, China

Gordon Young, Wilfrid Laurier University, Waterloo, Canada

TITLES IN PRINT IN THIS SERIES

A. Ismail-Zadeh, J. Urrutia Fucugauchi, A. Kijko, K. Takeuchi, and I. Zaliapin, Extreme Natural Hazards, Disaster Risks and Societal Implications.

J. Li, R. Swinbank, R. Grotjahn, and H. Volkert, Dynamics and Predictability of Large-Scale, High-Impact Weather and Climate Events. 


\title{
Dynamics and Predictability of Large-Scale High-Impact Weather and Climate Events
}

\author{
EDITED BY \\ JIANPING LI \\ Beijing Normal University \\ RICHARD SWINBANK \\ Met Office \\ RICHARD GROTJAHN \\ University of California, Davis \\ HANS VOLKERT \\ Deutsche Zentrum für Luft- und Raumfahrt
}


Cambridge University Press

978-1-107-07142-1 - Dynamics and Predictability of Large-Scale High-Impact Weather and Climate Events

Edited by Jianping Li, Richard Swinbank, Richard Grotjahn and Hans Volkert

Frontmatter

More information

\section{CAMBRIDGE UNIVERSITY PRESS}

University Printing House, Cambridge CB2 8BS, United Kingdom

Cambridge University Press is part of the University of Cambridge.

It furthers the University's mission by disseminating knowledge in the pursuit of education, learning and research at the highest international levels of excellence.

www.cambridge.org

Information on this title: www.cambridge.org/9781107071421

(C) Cambridge University Press 2016

This publication is in copyright. Subject to statutory exception and to the provisions of relevant collective licensing agreements, no reproduction of any part may take place without the written permission of Cambridge University Press.

First published 2016

Printed in the United Kingdom by TJ International Ltd. Padstow Cornwall

A catalogue record for this publication is available from the British Library

Library of Congress Cataloguing in Publication data

Dynamics and predictability of large-scale high-impact weather and climate events / edited by Jianping Li, Beijing Normal University, Richard Swinbank, Met Office, Richard Grotjahn, University of California, Davis, Hans Volkert, Deutsche Zentrum für Luft- und Raumfahrt eV (DLR). pages $\mathrm{cm}$

Includes index.

ISBN 978-1-107-07142-1 (Hardback)

1. Severe storms-Forecasting. 2. Weather forecasting. I. Li, Jianping (Meteorology professor), editor. II. Swinbank, Richard,

editor. III. Grotjahn, Richard, editor. IV. Volkert, Hans, editor.

QC941.D96 2015

$551.55-\mathrm{dc} 23 \quad 2015023762$

\section{ISBN 978-1-107-07142-1 Hardback}

Cambridge University Press has no responsibility for the persistence or accuracy of URLs for external or third-party internet websites referred to in this publication, and does not guarantee that any content on such websites is, or will remain, accurate or appropriate. 
Cambridge University Press

978-1-107-07142-1 - Dynamics and Predictability of Large-Scale High-Impact Weather and Climate Events

Edited by Jianping Li, Richard Swinbank, Richard Grotjahn and Hans Volkert

Frontmatter

More information

\section{Contents}

Preface

Acknowledgments

page vii

List of contributors

Part I. Diagnostics and prediction of high-impact weather

1. Global prediction of high-impact weather: diagnosis and performance Mark Rodwell and Alan Thorpe

2. Severe weather diagnosis from the perspective of generalized slantwise vorticity development Guoxiong Wu, Yongjun Zheng, and Yimin Liu

3. Probabilistic extreme event attribution Pardeep Pall, Michael Wehner, and Dáithi Stone

4. Observed and projected changes in temperature and precipitation extremes Xuebin Zhang and Francis Zwiers

\section{Part II. High-impact weather in mid latitudes}

5. Rossby wave breaking: climatology, interaction with low-frequency climate variability, and links to extreme weather events Olivia Martius and Gwendal Rivière

6. The influence of jet stream regime on extreme weather events Nili Harnik, Chaim I. Garfinkel, and Orli Lachmy

7. Forecasting high-impact weather using ensemble prediction systems Richard Swinbank, Petra Friederichs, and Sabrina Wahl

8. Storm tracks, blocking, and climate change: a review Tim Woollings

9. The North Atlantic and Arctic Oscillations: climate variability, extremes, and stratospheretroposphere interaction Adam A. Scaife

\section{Part III. Tropical cyclones}

10. Opportunities and challenges in dynamical and predictability studies of tropical cyclone events Russell L. Elsberry and Hsiao-Chung Tsai 
Cambridge University Press

978-1-107-07142-1 - Dynamics and Predictability of Large-Scale High-Impact Weather and Climate Events

Edited by Jianping Li, Richard Swinbank, Richard Grotjahn and Hans Volkert

Frontmatter

More information

21. Key role of the Atlantic Multidecadal Oscillation in twentieth century drought and wet periods over the US Great Plains and the Sahel

Sumant Nigam and Alfredo Ruiz-Barradas

22. Floods and droughts along the Guinea Coast in connection with the South Atlantic Dipole Hyacinth C. Nnamchi and Jianping $L i$

23. The effect of global dynamical factors on the interannual variability of land-based rainfall

Peter G. Baines and Benjamin J. Henley

24. MJO and extreme weather/climate events Chidong Zhang

\section{Part VI. Asian monsoons}

25. Extreme weather and seasonal events during the Indian summer monsoon and prospects of improvement in their prediction skill under India's Monsoon Mission D. R. Sikka

26. Interannual variability and predictability of summer climate over the Northwest Pacific and East Asia

Shang-Ping Xie and Yu Kosaka

27. Impacts of annular modes on extreme climate events over the East Asian monsoon region Jianping $L i$

Color plate section between pages 210 and 211 
Cambridge University Press

978-1-107-07142-1 - Dynamics and Predictability of Large-Scale High-Impact Weather and Climate Events

Edited by Jianping Li, Richard Swinbank, Richard Grotjahn and Hans Volkert

Frontmatter

More information

\section{Preface}

In recent years, a significant number of high-impact weather and climate events have inflicted catastrophic property damage and loss of human life, and hindered socio-economic development. Tropical cyclones are some of the most damaging weather systems; recent examples include hurricane Katrina in the USA in 2005 and hurricane Sandy in the USA in 2012, while multiple typhoons affected China in 2012. Severe flooding occurred in Australia in 2010-11, Europe in 2002, China in 2012, and Pakistan in 2010; there were droughts in China in 2010-2011, the USA in 2012; heat waves swept across the United States in 2012 and freezing rain in China in 2008. "High-impact" events encompass not only severe or extreme weather, but also other weather and climate events that have a major socio-economic impact. Thus, further improving weather forecasting and climate prediction capabilities are not only the topics at the forefront of the atmospheric science community, but also increasingly important requirements of public meteorological services. However, it is undeniable that there is a need for greater scientific knowledge to underpin weather forecasts and climate predictions, especially, for high-impact weather and climate events. The main outcome of this deficiency is a lack of knowledge of the dynamic mechanism and predictability of high-impact weather and climate events.

In view of this, the International Commission on Dynamical Meteorology (ICDM) held a workshop on the subject of "Dynamics and predictability of high-impact weather and climate events" on 6-9 August 2012, in Kunming, China. The ICDM is one of the commissions of the International Association of Meteorology and Atmospheric Sciences (IAMAS), which is in turn a constituent association of the International Union of Geodesy and Geophysics (IUGG). The commission is composed of international scientists who are committed to pursuing and cooperating in the science of dynamical meteorology. In the past, the ICDM has made very valuable contributions to the observation, research, analysis, and simulation of atmospheric dynamics across a range of time and space scales, and coupling of the atmosphere to the ocean. In turn those developments have led to improved skill in weather, climate, and environmental prediction for the benefit of society. The ICDM sponsors symposia that are held during the biennial IUGG General Assemblies and IAMAS Assemblies. The workshop was an additional event, intended to foster further understanding of the relevant dynamical and physical mechanisms that lead to extreme weather and climate events.

This book is largely based on the invited lectures presented at that workshop. It sets out our current understanding of the critical issues concerning dynamics and predictability of global and regional high-impact weather and climate events. Our aim is to summarize relevant newest advances in this field, and to enhance the understanding of physical processes associated with these events. The book covers a range of important research issues related to extreme events, including tropical cyclones, Asian monsoon, Madden-Julian oscillation, and annular modes, as well as the predictability of high-impact weather and climate events on multiple time scales. The combination of leading scientists and highly topical subject matter makes the book particularly appropriate for inclusion in the IUGG Special Publications series.

There have been a number of recent books describing high-impact or extreme weather and climate events. Many of these books describe extreme events with simple and vivid images to popularize the science, or they focus on the social and economic impacts of extreme events. However, this book focuses on the dynamics and predictability of extreme events, and assumes prior knowledge of the fundamentals of atmospheric dynamics. It may be the first comprehensive book dedicated to almost all key topics of extreme weather and climate events, with the main focus on synoptic and larger-scale phenomena. Our intention is not to create a geographical survey of extreme events, but rather to use specific examples to illustrate broader dynamical causes of such events. We anticipate that the book will become an important reference for these particular areas of atmospheric science.

This book is organized into six parts, comprising 27 peer-reviewed chapters. Part I, Diagnostics and prediction of high-impact weather, introduces the numerical prediction of high-impact weather, and discusses projected changes in climate extremes. Part II, High-impact weather in mid latitudes, discusses the relationship between variations in mid-latitude jet streams and severe weather events, troposphere-stratosphere interaction, and the use of probabilistic prediction techniques. Part III, Tropical cyclones, covers many aspects of the life-cycle of tropical cyclones and prediction of the associated severe weather. Part IV, Heat waves and cold-air outbreaks, analyses summer heat and drought and their relationship with both 
Cambridge University Press

978-1-107-07142-1 - Dynamics and Predictability of Large-Scale High-Impact Weather and Climate Events

Edited by Jianping Li, Richard Swinbank, Richard Grotjahn and Hans Volkert

Frontmatter

More information

large-scale dynamics and surface conditions. It also explores related mechanisms linked to cold-air outbreaks over Asia. Part V, Ocean connections, explores how the ocean contributes to extreme weather and climate events, with a primary focus on extended drought and wet periods. Part VI, Asian monsoons, surveys the prediction of extreme events associated with the Indian monsoon, and wider connections with East Asia, the Northwest Pacific, and links with annular modes.

The main authors for each chapter are leading scientists in the field of weather and climate extremes. The book comprises the most important content of the ICDM 2012 workshop, including contributions from the invited lecturers and other selected participants However, in order to produce a more balanced book, additional contributions were solicited from other leading researchers in the field.

The book is intended for graduate students and postdoctoral and other researchers who are interested in atmospheric dynamics and its relevance to the prediction of extreme events, across a range of time scales, from shortterm weather forecasting to climate prediction. The book will provide a theoretical reference for improving researchers' understanding of the critical issues concerning the dynamics and predictability of global and regional high-impact weather and climate events. The improved understanding will also help relevant managers and policy makers to make proper decisions to manage risk and prevent or mitigate disasters.

We hope you enjoy reading this book. 
Cambridge University Press

978-1-107-07142-1 - Dynamics and Predictability of Large-Scale High-Impact Weather and Climate Events

Edited by Jianping Li, Richard Swinbank, Richard Grotjahn and Hans Volkert

Frontmatter

More information

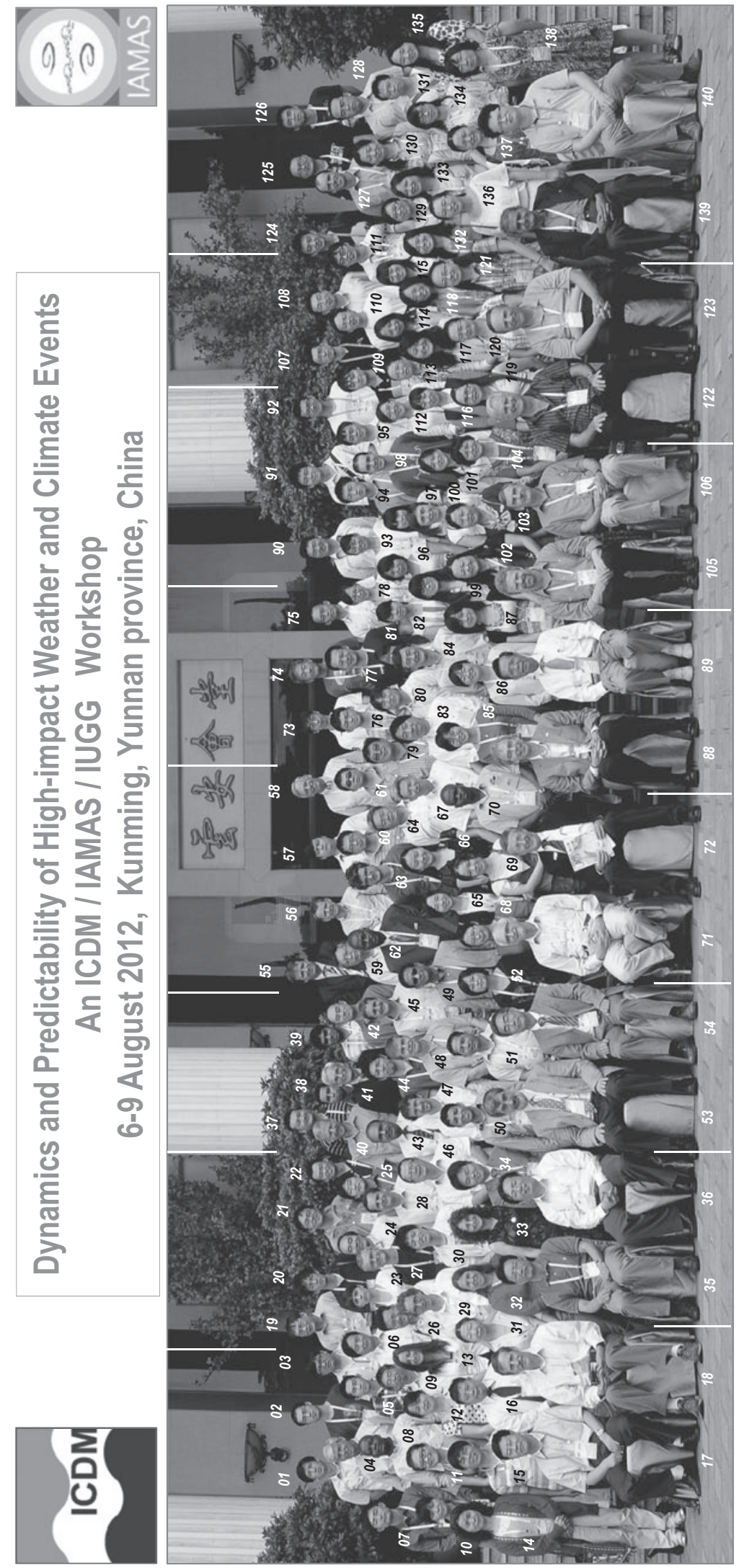

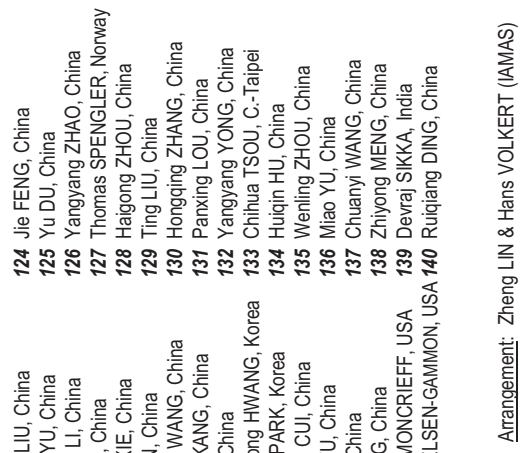

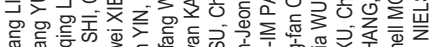

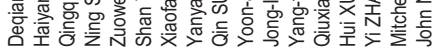

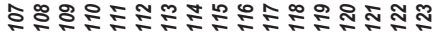

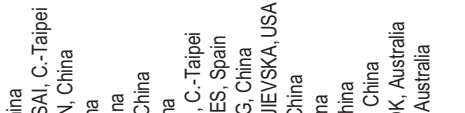

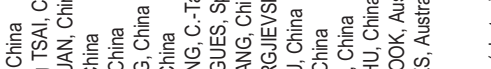

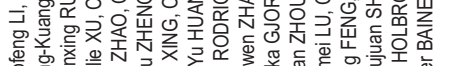

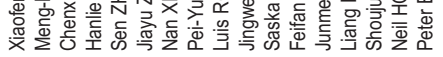

ஃட人்

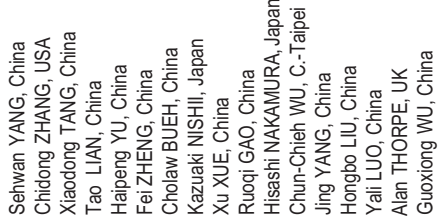

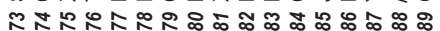

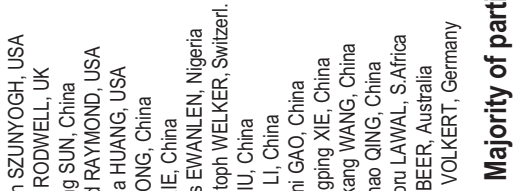

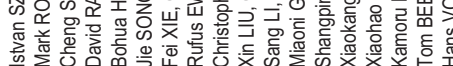

敋的品品8

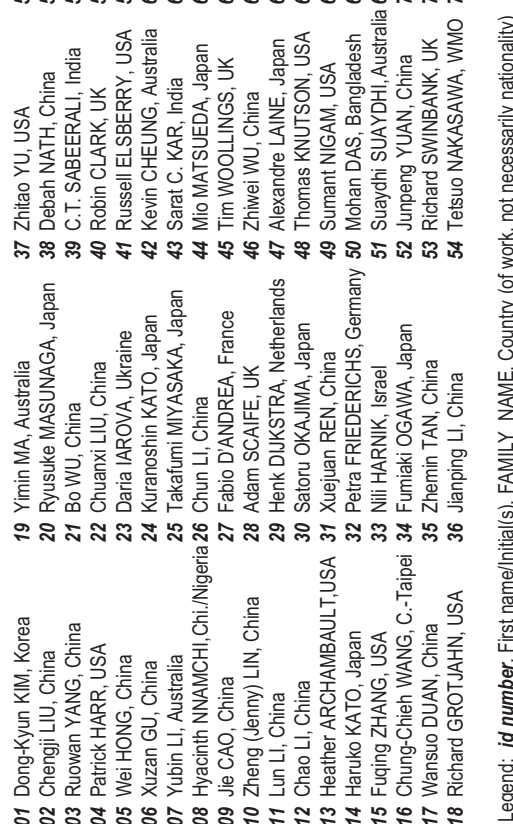


Cambridge University Press

978-1-107-07142-1 - Dynamics and Predictability of Large-Scale High-Impact Weather and Climate Events

Edited by Jianping Li, Richard Swinbank, Richard Grotjahn and Hans Volkert

Frontmatter

More information

\section{Acknowledgments}

This book could not have been completed without the strong support of the international and national organizations, international and national projects (Fig. P1) as follows:

- The International Union of Geodesy and Geophysics (IUGG);

- The Observing System Research and Predictability Experiment (THORPEX) of the World Weather Research Programme (WWRP);

- The World Climate Research Programme (WCRP);

- The Chinese Association for Science and Technology (CAST);

- The Chinese National Committee for IUGG;

- The Chinese Academy of Sciences (CAS);

- The National Natural-Science Foundation of China (NSFC);

- The State Key Laboratory of Numerical Modelling for Atmospheric Sciences and Geophysical Fluid Dynamics (LASG), Institute of Atmospheric Physics (IAP);
- The National Basic Research Program of China (973 Program): "Air-Land-Sea interactions in Asia and their role in the global change (ALS)" (2010CB950400);

- The NSFC Key Project: "New theory of planetary wave in non-uniform basic flow and interaction between $\mathrm{SH}$ and NH atmospheres" (41030961);

- The International Association of Meteorology and Atmospheric Sciences (IAMAS);

- The International Commission of Dynamical Meteorology (ICDM)/IAMAS;

- Nanjing University.

We sincerely thank all authors of the book chapters for their excellent contributions. This comprehensive book could not have been completed without their continued support. We are most grateful to the reviewers of the chapters for their constructive reviews, which helped improve upon the original manuscripts. The chapter reviewers were as follows: Peter G. Baines, Tom Beer,

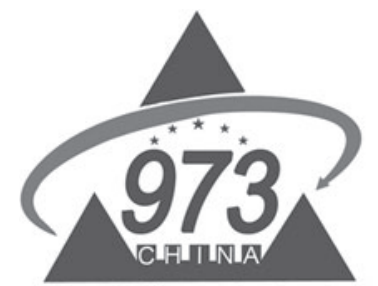

国家重点基础研究发展计划
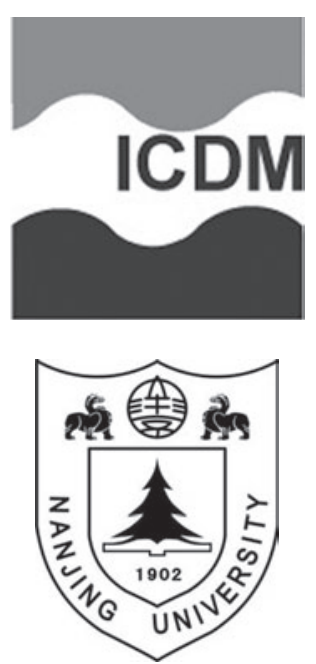
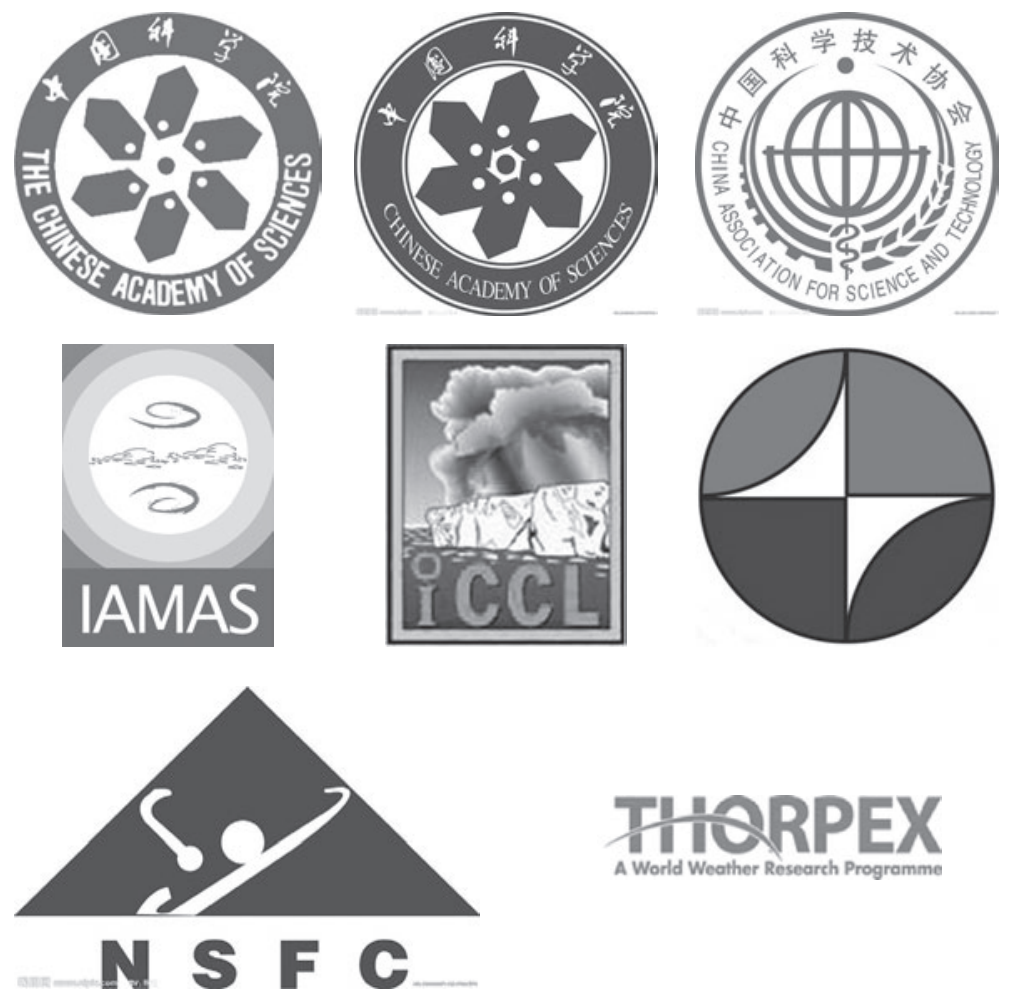


WCRP

Figure P1. Logos of the relevant supporting organizations and projects for the book. 
Cambridge University Press

978-1-107-07142-1 - Dynamics and Predictability of Large-Scale High-Impact Weather and Climate Events

Edited by Jianping Li, Richard Swinbank, Richard Grotjahn and Hans Volkert

Frontmatter

More information

Robin Clark, Henk Dijkstra, Russell L. Elsberry, Juan Feng, Petra Friederichs, Richard Grotjahn, Nili Harnik, Patrick Harr, Bohua Huang, Jianping Li, Jian Ling, Yimin Liu, Olivia Martius, Mu Mu, Hisashi Nakamura, Tetsuo Nakazawa, John W. Nielsen-Gammon, Xiaohao Qin, Mark Rodwell, Adam A. Scaife, Richard Swinbank, Zhe-Min Tan, Tim Woollings, Chun-Chieh $\mathrm{Wu}$, Zhiwei $\mathrm{Wu}$, Shang-Ping Xie, and Feifan Zhou.

Special thanks go to Susan Francis, Zoë Pruce, Cassi Roberts, Karyn Bailey, and Rosina Piovani of Cambridge University Press for their guidance throughout the production of the book. We are very grateful to Zheng Lin, Chuanyi Wang, and Wenling Zhou for their excellent support with the organization of the workshop. We are particularly thankful to Chuanyi Wang for her coordinating efforts in the chapter collecting, language editing and reviewing processes. We also thank Wenling Zhou and Xiaoxi $\mathrm{Li}$ for their valuable assistance at the early and late stages of book preparation. We also thank Ruiqiang Ding, Wansuo Duan, Qing Bao, Juan Feng, Xiaofeng Li, Xiaohao Qin, Jie Song, Cheng Sun, Bo Wu, Fei Xie, Feifan Zhou, and Yanjie Li for their helpful assistance. 
Cambridge University Press

978-1-107-07142-1 - Dynamics and Predictability of Large-Scale High-Impact Weather and Climate Events

Edited by Jianping Li, Richard Swinbank, Richard Grotjahn and Hans Volkert

Frontmatter

More information

\section{Contributors}

\section{Oscar Alves}

Centre for Australian Weather and Climate Research, Australia

\section{Fabio d'Andrea}

Laboratoire de Meteorologie Dynamique, Ecole Normale

Superieure, France

\section{Heather Archambault}

National Oceanic and Atmospheric Administration, USA

\section{Peter Baines}

University of Melbourne, Australia

\section{Tom Beer}

Centre for Australian Weather and Climate Research, Australia

\section{Robin Clark}

Met Office Hadley Centre, UK

\section{Henk Dijkstra}

Utrecht University, Netherlands

\section{Philippe Drobinski}

Laboratoire de Meteorologie Dynamique, Ecole Normale Superieure, France

\section{Russell Elsberry}

Naval Postgraduate School, USA

\section{Petra Friederichs}

University of Bonn, Germany

\section{Chaim Garfinkel}

Hebrew University, Jerusalem, Israel

\section{Richard Grotjahn}

University of California, Davis, USA

\section{Nili Harnik}

Tel Aviv University, Israel

\section{Patrick Harr}

National Science Foundation, USA

\section{Benjamin J. Henley}

University of Melbourne, Australia

\section{Yi-Hsuan Huang}

National Taiwan University

\section{Yu Kosaka}

Scripps Institution of Oceanography, USA

\section{Orli Lachmy}

Tel Aviv University, Israel

\section{Jianping Li}

Beijing Normal University, China

\section{Yimin Liu}

Institute of Atmospheric Physics, China

Olivia Martius

University of Bern, Switzerland

\section{Christopher Melhauser}

Pennsylvania State University, USA

Erin B. Munsell

Pennsylvania State University, USA

\section{Hisashi Nakamura}

University of Tokyo, Japan

Sumant Nigam

University of Maryland, USA

\section{Kazuaki Nishii}

University of Tokyo, Japan

\section{Hyacinth C. Nnamchi}

University of Nigeria, Nigeria

Yvan J. Orsolini

Norwegian Institute for Air Research, and University of Bergen, Norway

\section{Pardeep Pall}

Lawrence Berkeley National Laboratory, USA

\section{Gwendal Rivière}

Laboratoire de Météorologie Dynamique, Ecole Normale Superieure, France

\section{Mark Rodwell}

European Centre for Medium-range Forecasts, UK

\section{Alfredo Ruiz-Barradas}

University of Maryland, USA

Adam A. Scaife

Met Office Hadley Centre, UK

\section{R. Sikka}

Indian Institute of Tropical Meteorology, India

\section{Jason A. Sippel}

I. M. Systems Group, and National Oceanic and Atmospheric Administration, USA

\section{Marc Stéfanon}

Laboratoire des Sciences du Climat et de l'Environment Institut Pierre Simon Laplace, France

\section{Dáithí Stone}

Lawrence Berkeley National Laboratory, USA 
Cambridge University Press

978-1-107-07142-1 - Dynamics and Predictability of Large-Scale High-Impact Weather and Climate Events

Edited by Jianping Li, Richard Swinbank, Richard Grotjahn and Hans Volkert

Frontmatter

More information

\section{Y. Qiang Sun}

Pennsylvania State University, USA

Richard Swinbank

Met Office, UK

Koutarou Takaya

Kyoto Sangyo University, Japan

\section{Zhe-Min Tan}

Nanjing University, China

\section{Dandan Tao}

Pennsylvania State University, USA

\section{Alan Thorpe}

European Centre for Medium-range Forecasts, UK

\section{Hsiao-Chung Tsai}

Naval Postgraduate School Monterey, USA

Hans Volkert

Deutsches Zentrum für Luft-und Raumfahrt, Germany

\section{Sabrina Wahl}

University of Bonn, Germany

\section{Lin Wang}

University of Tokyo, Japan and Institute of Atmospheric Physics, China

\section{Michael Wehner}

Lawrence Berkeley National Laboratory, USA

\section{Yonghui Weng}

Pennsylvania State University, USA

Tim Woollings

University of Oxford, UK

Chun-Chieh Wu

National Taiwan University

\section{Guoxiong Wu}

Institute of Atmospheric Physics, China

\section{Zhiwei Wu}

Nanjing University of Information Science and Technology, China

\section{Shang-Ping Xie}

Scripps Institution of Oceanography, USA

\section{Chidong Zhang}

University of Miami, USA

Fuqing Zhang

Pennsylvania State University, USA

Xuebin Zhang

Environment Canada, Canada

\section{Yongjun Zheng}

Chinese Academy of Meteorological Sciences, China

\section{Francis Zwiers}

University of Victoria, Canada 